\title{
Corpus luteum function in the pig: progesterone profiles of cyclic and pregnant gilts
}

\author{
J. VAN DER MEULEN, F. A. HELMOND \& C. P. J. OUDENAARDEN \\ Department of Animal Physiology, Wageningen Agricultural University, Haarweg 10, NL \\ 6709 PJ Wageningen, Netherlands
}

Received 20 June 1989; accepted 8 November 1989

\begin{abstract}
Progesterone profiles of pregnant and cyclic gilts were compared. From day 14 onwards a significant difference in progesterone concentration existed between cyclic $(n=7)$ and pregnant gilts $(n=6)(P<0.05)$. This indicates that corpus luteum $(C L)$ rescue during pregnancy occurs before day 14 . In one of the inseminated gilts, the progesterone concentration declined on day 27 and the gilt returned to oestrus on day 30 . The progesterone and oestrone sulphate profiles of this gilt indicated that return to oestrus may have been caused by embryonic loss before day 14 after a first signal for CL maintenance has been generated. Another gilt aborted on day 27 . The data of this gilt indicate that pregnancy failure may have been caused by a maternal malfunction.
\end{abstract}

Keywords: progesterone, cycle, pregnancy, pig

\section{Introduction}

During pregnancy in the pig, progesterone is necessary for the secretion of endometrial histotrophe (required for blastocyst growth) and suppression of uterine contractile activity. There is a minimum daily progesterone requirement for the maintenance of pregnancy of 12.7-15.9 nmol $\mathrm{l}^{-1}$ (Ellicott \& Dziuk, 1973). A decrease of progesterone below this level by ovariectomy (Ellicott \& Dziuk, 1973; First \& Staigmiller, 1973; Nara et al., 1981), removal of the corpora lutea (CL) (Nara et al., 1981) or injection of $\mathrm{PGF}_{2 \alpha}$ (Diehl \& Day, 1974) results in termination of pregnancy and return to oestrus. For the whole duration of pregnancy in the pig, the CL are the main source of progesterone. At least $5 \mathrm{CL}$ are needed for the production of sufficient progesterone to maintain pregnancy (Du Mesnil du Buisson \& Dauzier, 1959; Martin et al., 1977).

A prerequisite for the establishment and maintenance of pregnancy is the rescue of the CL in early pregnancy. In non-pregnant pigs the life-span of the CL is limited by the luteolytic action of $\mathrm{PGF}_{2 \alpha}$ (Bazer et al., 1982), which is elevated in the utero-ovarian vein (UOV) between days 13-17 (Moeljono et al., 1977). As a result of an anti-luteolytic action of the blastocysts UOV PGF $_{2 \alpha}$ concentration remains 
low during pregnancy and $\mathrm{PGF}_{2 \alpha}$ is prevented to reach the $\mathrm{CL}$ in sufficient amounts to cause luteal regression. In this way progesterone secretion continues.

In this study the time period of maintenance of CL function was investigated by measuring progesterone concentrations of cyclic and pregnant gilts. The progesterone and oestrone sulphate concentrations of two gilts in which pregnancy failed before day 30 were compared with those of pregnant gilts.

\section{Materials and methods}

\section{Animals and experimental design}

Fifteen crossbred gilts (Great Yorkshire $\times$ Dutch Landrace) which had shown two or more normal oestrous cycles (18-22 days) were used. The gilts were checked for oestrus with a vasectomized boar twice daily (09:00 and 15:00 h). At least 5 days before expected oestrus, they were fitted with an indwelling jugular vein catheter (PVC, $1.0 \mathrm{~mm}$ i.d., $1.5 \mathrm{~mm}$ o.d.). Blood samples were collected around oestrus three times a day $(09: 00,12: 00$ and 15:00 h) and from day 4 once each day (09:00 h). At the time of observing first standing heat (day 0) $100 \mu \mathrm{g}$ gonadotropin releasing hormone (GnRH) analogue (Ovalyse; Upjohn Company, Ede, Netherlands) were injected intramuscularly. Artificial insemination (AI) was carried out in 8 gilts on day 1 , about $26 \mathrm{~h}$ after observing first standing heat. Blood sampling and checking for oestrus continued, until the cyclic gilts $(n=7)$ returned to oestrus and until the pregnant gilts $(n=8)$ were slaughtered on day 35 .

One gilt (No 161) returned to oestrus on day 30 and another gilt (No 11) aborted on day 28.

\section{Hormone analysis}

All blood samples were collected into heparinized tubes and centrifuged; plasma was stored at $-20^{\circ} \mathrm{C}$ until further analysis.

Plasma concentrations of progesterone were measured in all samples by radioimmunoassay (RIA) (Helmond et al., 1980), using a specific rabbit antiserum against 4-pregnene-6 $\beta$-o1-3, 20-dione-hemisuccinate-BSA. The main cross-reacting steroids were pregnenolone $(98.0 \%)$, corticosterone $(2.7 \%), \quad 17 \alpha$ hydroxyprogesterone $(1.5 \%)$ and $20 \alpha$-hydroxy-4-pregnen-3-one, cortisol, oestrone, oestradiol-17 $\beta$, oestradiol-17 $\alpha$, oestriol, androstenedione, dehydroandrosterone and testosterone (all $<0.2 \%$ ). The antiserum was used in a working dilution of 1:15 000. The sensitivity of the assay was $0.3 \mathrm{nmol} 1^{-1}$ at the $90 \% \mathrm{~B} / \mathrm{B}_{\mathrm{o}}$ level. The intra-assay coefficient of variation was $7.1 \%$ and the inter-assay coefficient of variation was $12.5 \%$.

Plasma concentrations of luteinizing hormone $(\mathrm{LH})$ were measured in the samples collected around oestrus by a double-antibody RIA (Niswender et al., 1970), using pig LH (LER 786-3, potency $0.65 \times \mathrm{NIH}-\mathrm{LH}-\mathrm{S1}$ ) as a standard and for iodination. Anti-ovine LH 614 IV was used at a 1:30 000 working dilution and goat anti-rabbit immunoglobulin as the second antibody. The sensitivity of the assay was $23.3 \mathrm{pmol}$ 
$1^{-1}$ at the $90 \% \mathrm{~B} / \mathrm{B}_{0}$ level. The intra-assay coefficient of variation was $13.8 \%$ and the inter-assay coefficient of variation was $15.1 \%$.

Plasma concentrations of oestrone sulphate were measured in all samples by RIA after extraction and column chromatography, using a modification of the method described by Helmond et al. (1980). Samples of $100 \mu \mathrm{l}$ were diluted in $900 \mu \mathrm{l}$ phosphate buffer with $0.1 \%$ BSA and mixed with $1 \mathrm{ml}$ acetate buffer $(0.15 \mathrm{M}, \mathrm{pH} 4.1)$. The samples were incubated overnight at $37{ }^{\circ} \mathrm{C}$ in the dark after addition of an enzyme preparation (3100 units $\mathrm{ml}^{-1}$ sulphatase and 13000 units $\mathrm{ml}^{-1} \beta$ glucuronidase from the snail Helix pomatia; Sigma, St. Louis, MO, USA) to convert sulphated oestrogens into free oestrogens. The samples were extracted three times with diethyl ether $(4 \mathrm{ml})$ after the addition of $1000 \mathrm{cpm}$ of $\left[2,4,6,7-{ }^{3} \mathrm{H}\right]$-oestrone (Radiochemical Centre, Amersham, UK) for estimation of procedural losses. The residues of the diethyl ether extracts were evaporated under a stream of nitrogen, redissolved in $250 \mu$ l toluene:methanol $(9: 1, \mathrm{v} / \mathrm{v})$ and applied to chromatography columns $(8.0 \times 0.7 \mathrm{~cm})$ packed with Sephadex LH-20 (Pharmacia, Uppsala, Sweden; eluting solvent: toluene:methanol 9:1, v/v). The first $1 \mathrm{ml}$ fraction was discarded and oestrone (E1) was eluted in the next $3 \mathrm{ml}$ fraction. These E1 fractions were dried under a stream of nitrogen and redissolved in $500 \mu \mathrm{l}$ ethanol. An aliquot of $150 \mu \mathrm{l}$ was taken in order to determine the recovery of [ $\left.{ }^{3} \mathrm{H}\right]-\mathrm{E} 1(78 \%)$. E1 concentrations were measured in duplo (two aliquots of $150 \mu \mathrm{l}$ ) by RIA using a specific rabbit antiserum against 6-keto-oestrone 6-CMO-BSA. The main cross-reacting steroid was oestradiol $(0.45 \%)$. The antiserum was used in a working dilution of 1:30 000. The sensitivity of the assay was $35.5 \mathrm{pmol} 1^{-1}$ at the $90 \% \mathrm{~B} / \mathrm{B} 0$ level. The intra-assay coefficient of variation was $12.4 \%$ and the inter-assay coefficient of variation was $15.7 \%$.

\section{Statistical analysis}

Differences in $\mathrm{LH}$ and progesterone concentration of pregnant and cyclic gilts were tested for significance after In transformation of the data by Student's $t$ test (SPSS Inc., 1988).

\section{Results}

In all gilts the highest $\mathrm{LH}$ concentrations were measured $3 \mathrm{~h}$ after injecting the GnRH analogue. The LH peaks did not differ between cyclic (Fig. 1) and pregnant gilts (Fig. 2).

In both groups, progesterone concentrations increased above $3.2 \mathrm{nmol} \mathrm{l}^{-1}$ on day 2 . In the group of the 7 cyclic gilts, the highest progesterone concentration was measured on day $13\left(110.5 \mathrm{nmol}^{-1}\right)$. Thereafter the progesterone concentration declined and returned to basal level on day 19 (Fig. 1).

In the group of the 6 gilts pregnant up to day 35 , the highest progesterone concentration was measured on day $16\left(161.6 \mathrm{nmol}^{-1}\right)$ and progesterone remained at a level of $104.9 \mathrm{nmol}^{-1}$ (range 86.2-141.2) from day 19 onwards. From day 14 there was a significant difference in progesterone level between the cyclic and preg- 


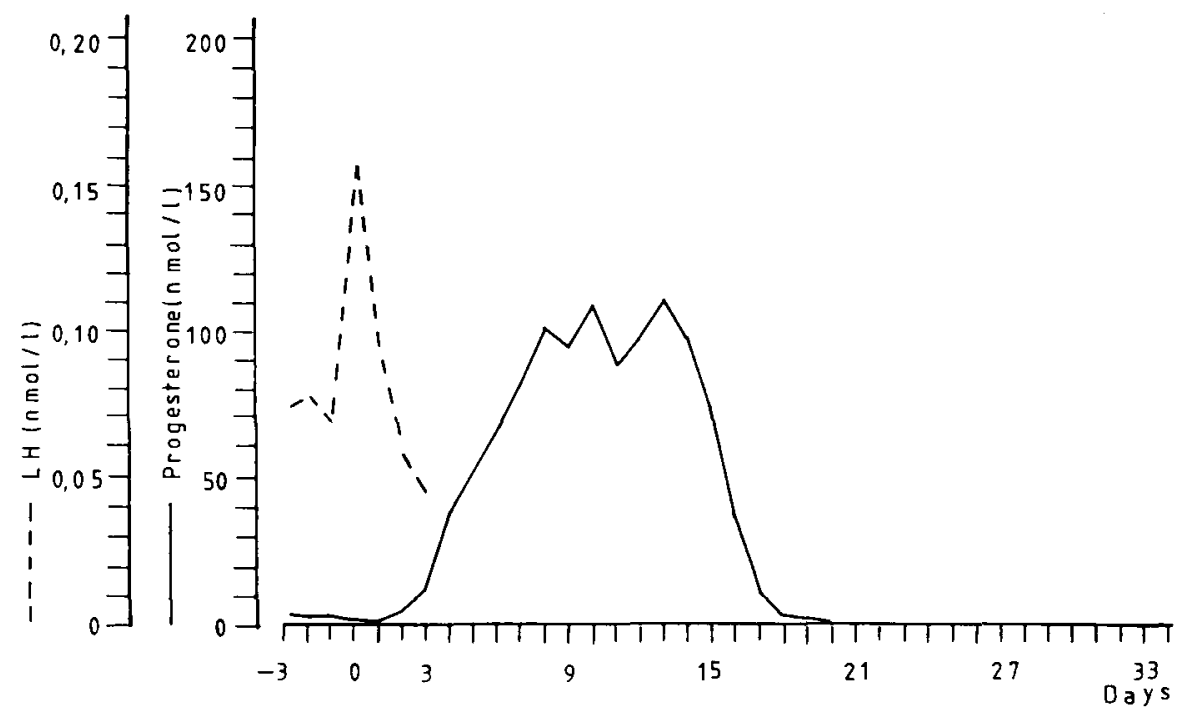

Fig. 1. The LH profile around oestrus and the progesterone profile of 7 cyclic gilts.

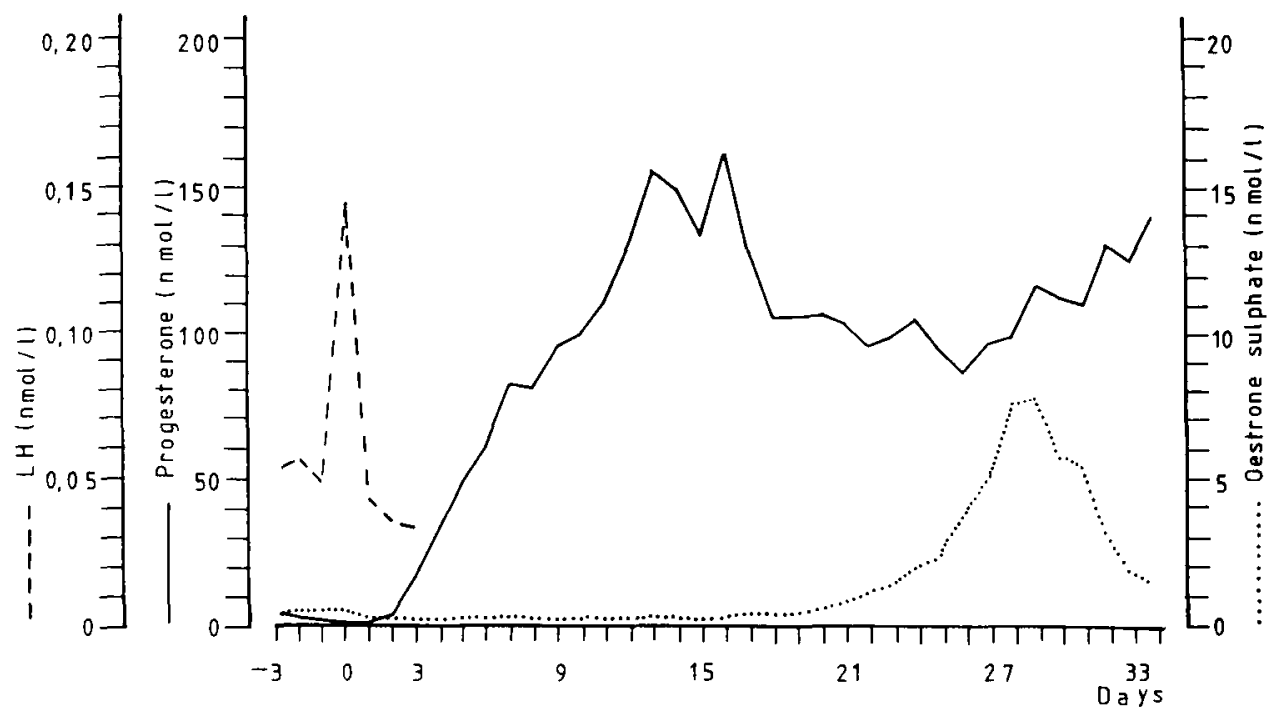

Fig. 2. The LH profile around oestrus and the progesterone and oestrone sulphate profiles of 6 pregnant gilts. 


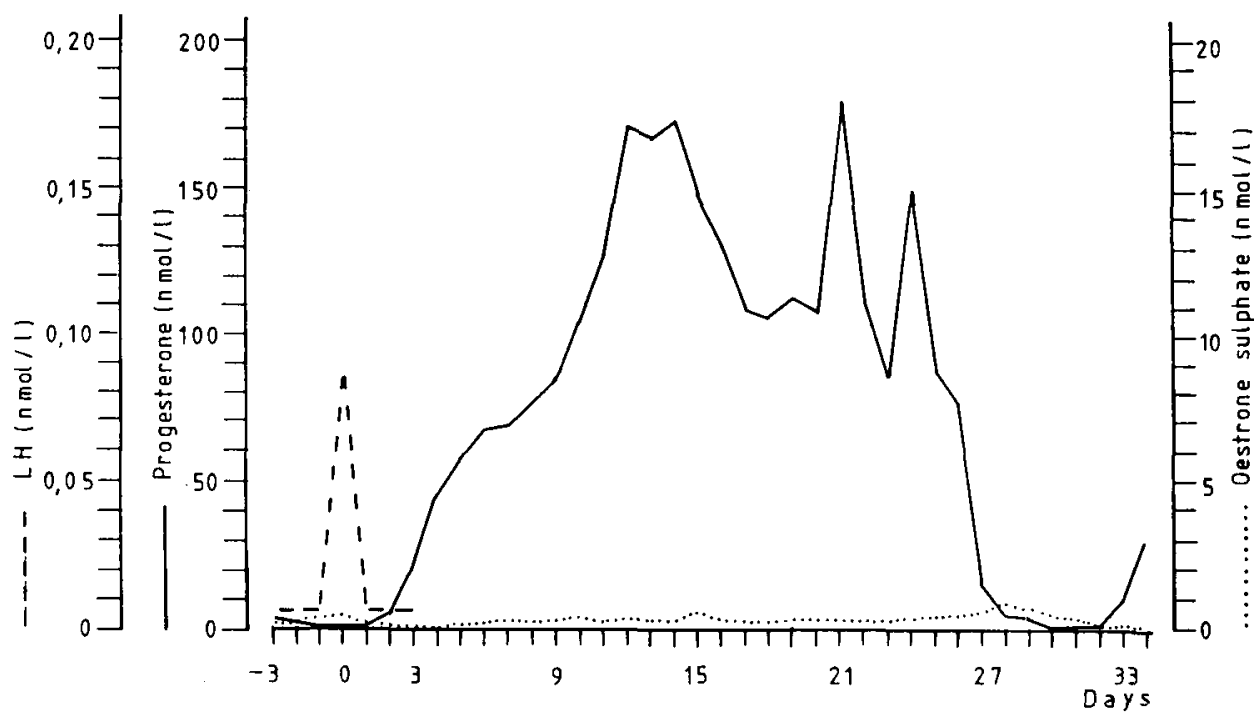

Fig. 3. The LH profile around oestrus and the progesterone and oestrone sulphate profiles of gilt No 161 , which returned to oestrus on day 30 .

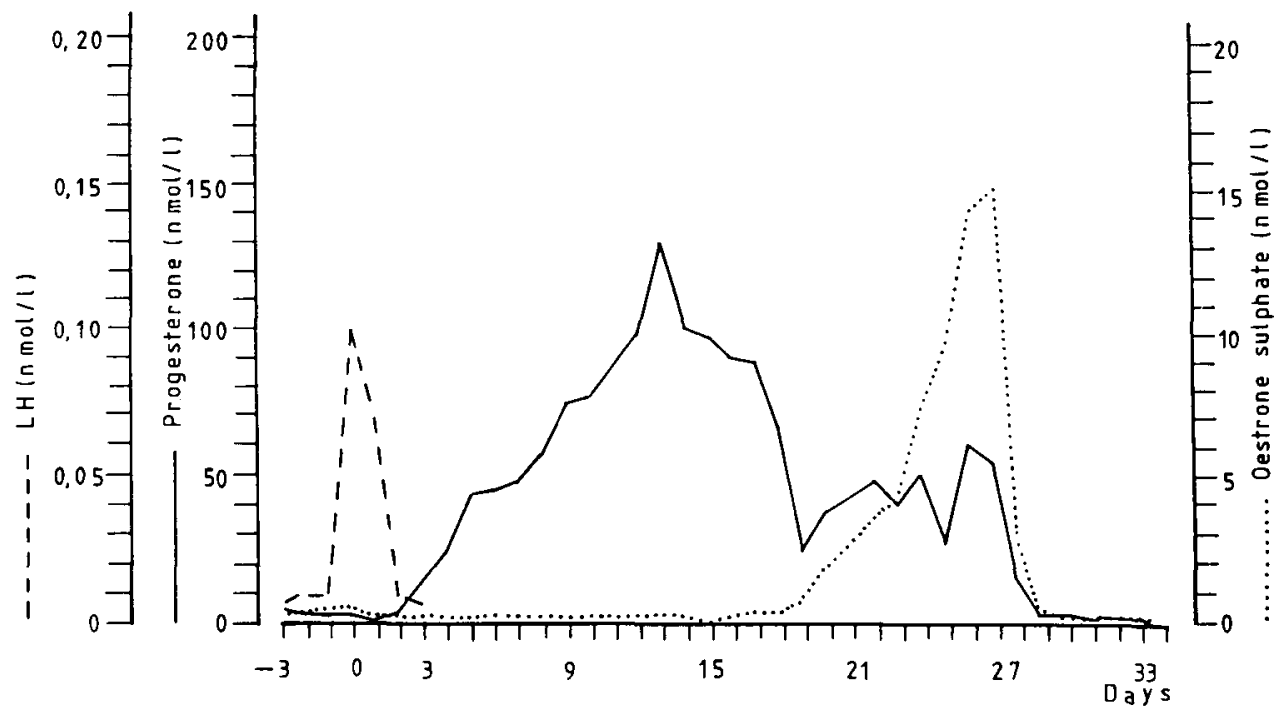

Fig. 4. The LH profile around oestrus and the progesterone and oestrone sulphate profiles of gilt No 11 , which aborted on day 28 . 
nant gilts (day 14 and 15: $P<0.05$; day 16: $P<0.01$ ). In pregnant gilts the oestrone sulphate concentration increased from day 19 , reached a maximum on day 29 (7.8 nmol 1-1) and declined thereafter (Fig. 2).

In gilt No 161 the progesterone concentration was highest on day $14(173.2 \mathrm{nmol}$ $1^{-1}$ ) and remained at a level of $102.1 \mathrm{nmol} \mathrm{l}^{-1}$ (range 76.6-110.3) from day 21 onwards. The oestrone sulphate concentration did not increase but remained at basal levels. On day 27 the progesterone concentration suddenly declined to basal values. Around day 28 the oestrone sulphate concentration was slightly increased. The gilt returned to oestrus on day 30 and the progesterone concentration started to increase again from day 33 (Fig. 3).

In gilt No 11 the progesterone concentration was highest on day $13(130.0 \mathrm{nmol}$ $\mathrm{1}^{-1}$ ) and fluctuated between day 19 to 27 around a level of $45 \mathrm{nmol} \mathrm{1}^{-1}$ (range 24.261.4). From day 19 the oestrone sulphate level increased to a maximum of $14.9 \mathrm{nmol}$ $1^{-1}$ on day 27 . On day 28 both progesterone and oestrone sulphate concentrations suddenly dropped (Fig. 4). On this day, six aborted macroscopically normal foetuses were found. After the abortion the gilt was not seen in oestrus up to slaughter on day 35 .

\section{Discussion}

The progesterone profiles of the cyclic and pregnant gilts are comparable with those reported before (Stabenfeldt et al., 1969; Guthrie et al., 1972; Henricks et al., 1972; Ellendorff et al., 1976; King \& Rajamahendran, 1988). The oestrone sulphate profiles of the pregnant gilts also correspond with earlier investigations (Robertson \& King, 1974; Horne et al., 1983; Hattersley et al., 1980). However, the time of the highest levels of progesterone and oestrone sulphate, as well as the first time that pregnant and cyclic progesterone levels differ, may vary for one or two days. In our study a significant difference between the progesterone levels of cyclic and pregnant gilts exists at day 14 . These progesterone profiles indicate that $C L$ regression during pregnancy has to be prevented already before day 14 . This is in agreement with the observation of Dhindsa \& Dziuk (1968) that blastocysts must be present in both uterine horns between days 10 and 12 for continuation of CL function.

In commercial units there are two distinct periods of returning to oestrus after service (Glossop \& Foulkes, 1988). The major part of the sows returns to oestrus on day $20.7 \pm 1.4$ (range 17-23), and a second group (25.6\%) returns on day 26.5 \pm 2.3 (range 24-31). In our study gilt No 161 returned to oestrus during the second period on day 30. This gilt did not show an increase in oestrone sulphate concentration. This suggests that this gilt may have been pregnant until day 13, since in gilts in which the blastocysts were flushed out of both horns on days 12-13 and which returned to oestrus on day $28.4 \pm 2.6$ (van der Meulen et al., 1988), oestrone sulphate concentrations were also not elevated (J. van der Meulen, unpublished data). The blastocysts of this gilt may have generated a first signal for the maintenance of CL function, but they have probably failed to generate a second signal on days 14-16 (Geisert et al., 1987).

In gilt No 11, in contrast to gilt No 161 , the oestrone sulphate concentration in- 
creased from day 19 to 27 and did not deviate from that of pregnant gilts. From day 19 the progesterone level of this gilt varied around $45 \mathrm{nmol} \mathrm{l}^{-1}$, which is relatively low, compared with the progesterone concentration of pregnant gilts, but still higher than the minimum daily progesterone requirement for maintenance of pregnancy (Ellicott \& Dziuk, 1973). The normal oestrone sulphate concentration and the normal appearance of the aborted foetuses indicate a normal embryonic development until day 27. Although an embryonic malfunction cannot be excluded, the relatively low progesterone level and the failure to return to oestrus after abortion indicate a maternal cause for pregnancy failure in this gilt.

The data of gilt No 161 support the suggestion of Glossup \& Foulkes (1988) that return to oestrus after service on days $24-31$ is caused by embryonic loss. This embryonic loss may already occur around day 14-16 after a first signal for CL rescue has been generated.

\section{Acknowledgements}

The authors thank Dr L. E. Reichert for purified pig LH, Dr M. Ph. J. Hovius (Upjohn Company) for the GnRH analogue, Mr M. Hol for participating in this study and $\mathrm{Mr}$ J. van Brakel for preparing the illustrations. This work was carried out as a project of the Research Group on Early Pregnancy of the Wageningen Agricultural University.

\section{References}

Bazer, F. W., R. D. Geisert, W. W. Thatcher \& R. M. Roberts, 1982. The establishment and maintenance of pregnancy. In: D. J. A. Cole \& G. R. Foxcroft (Eds), Control of Pig Reproduction, pp. 227-262, Butterworths, London.

Dhindsa, D. S. \&. P. J. Dziuk, 1968. Effect on pregnancy in the pig after killing embryos or fetuses in one uterine horn in early gestation. Journal of Animal Science 27: 122-126.

Diehl, J. R. \& B. N. Day, 1974. Effect of prostaglandin $F_{2 \alpha}$ on luteal function in swine. Journal of Animal Science 39: 392-396.

Du Mesnil du Buisson, F. \& L. Dauzier, 1959. Controle mutuel de l'utérus et de l'ovaire chez la truie. Annales de Zootechnie, Série D, Supplément 8: 147-159.

Ellendorff, F., J. N. Meyer \& F. Elsaesser, 1976. Prospects and problems of pregnancy and fertility diagnosis in the pig by aid of progesterone determination. British Veterinary Journal 132: 543-550.

Ellicott, A. R. \& P. J. Dziuk, 1973. Minimum daily dose of progesterone and plasma concentration for maintenance of pregnancy in ovariectomized gilts. Biology of Reproduction 9: 300-304.

First, N. L. \& R. B. Staigmiller, 1973. Effects of ovariectomy, dexamethasone and progesterone on the maintenance of pregnancy in swine. Journal of Animal Science 37: 1191-1194.

Geisert, R. D., M. T. Zavy, R. P. Wettemann \& B. G. Biggers, 1987. Length of pseudopregnancy and pattern of uterine protein release as influenced by time and duration of oestrogen administration in the pig. Journal of Reproduction and Fertility 79: 163-172.

Glossop, C. E. \& J. A. Foulkes, 1988. Occurrence of two phases of return to oestrus in sows on commercial units. Veterinary Record 122: 163-164.

Guthrie, H. D., D. M. Hendricks \& D. L. Handlin, 1972. Plasma estrogen, progesterone and luteinizing hormone prior to estrus and during early pregnancy in pigs. Endocrinology 91: 675-679.

Hattersley, J. P., H. M. Drane, J. G. Matthews, A. E. Wrathall \& N. Saba, 1980. Estimation of oestrone sulphate in the serum of pregnant sows. Journal of Reproduction and Fertility 58: 7-12. 
Helmond, F. A., P. A. Simons \& P. R. Hein, 1980. The effect of progesterone on estrogen-induced luteinizing hormone and follicle-stimulating hormone release in the female rhesus monkey. Endocrinology 107: 478-485.

Henricks, D. M., H. D. Guthrie \& D. L. Handlin, 1972. Plasma estrogen, progesterone and luteinizing hormone levels during the estrous cycle in pigs. Biology of Reproduction 6: 210-218.

Horne, C., B. P. Chew, B. S. Wiseman \& P. J. Dziuk, 1983. Relationship between the level of estrone sulfate in the plasma and the number of fetuses during pregnancy in the gilt. Biology of Reproduction 29: 56-62.

King, G. J. \& R. Rajamahendran, 1988. Comparison of plasma progesterone profiles in cyclic, pregnant, pseudopregnant and hysterectomized pigs between 8 and 27 days after oestrus. Journal of Endocrinology 119: 111-116.

Martin, P. A., H. W. Norton \& P. J. Dziuk, 1977. The effect of corpora lutea induced during pregnancy on the length of gestation in the pig. Biology of Reproduction 17: 712-717.

Meulen, J. van der, F. A. Helmond \& C. P. J. Oudenaarden, 1988. Effect of flushing of blastocysts on Days 10-13 on the life-span of the corpora lutea in the pig. Journal of Reproduction and Fertility 84: $157-162$.

Moeljono, M. P. E., W. W. Thatcher, F. W. Bazer, M. Frank, L. J. Owens \& C. J. Wilcox, 1977. A study of prostaglandin $\mathrm{F}_{2 \alpha}$ as the luteolysin in swine. II. Characterization and comparison of prostaglandin $\mathrm{F}$, estrogens and progestin concentrations in utero-ovarian vein plasma of nonpregnant and pregnant gilts. Prostaglandins 14: 543-555.

Nara, B. S., D. Darmadja \& N. L. First, 1981. Effect of removal of follicles, corpora lutea or ovaries on maintenance of pregnancy in swine. Journal of Animal Science 52: 794-801.

Niswender, G. D., L. E. Reichert \& D. R. Zimmerman, 1970. Radioimmunoassay of serum levels of luteinizing hormone throughout the estrous cycle in pigs. Endocrinology 87: 576-580.

Robertson, H. A. \& G. J. King, 1974. Plasma concentrations of progesterone, oestrone, oestradiol-17 $\beta$ and of oestrone sulphate in the pig at implantation, during pregnancy and at parturition. Journal of Reproduction and Fertility 40: 133-141.

SPSS Inc., 1988. SPSS/PC + Base manual. SPSS Inc., Chicago, Illinois.

Stabenfeldt, G. H., E. L. Akins, L. L. Ewing \& M. C. Morrissette, 1969. Peripheral plasma progesterone levels in pigs during the oestrous cycle. Journal of Reproduction and Fertility 20: 443-449. 